\title{
Memoria oral del modelo de familia troncal en Els Ports de Morella: tensiones, cambios y continuidades para una generación de ruptura ${ }^{1}$
}

\author{
Oral memory of the souche family \\ model in Els Ports de Morella: \\ Tensions, changes and continuities \\ for a split generation
}

\author{
Albert Moncusí Ferré \\ Departament de Sociologia i Antropologia Social \\ Universitat de València
}

\section{RESUMEN}

Este texto tiene por objeto estudiar la reconstrucción del modelo de familia troncal a través de la memoria de personas que forman parte de la última generación que ha vivido su pleno funcionamiento de forma más o menos directa, en la comarca castellonense de Els Ports de Morella. Se realiza una síntesis de dicho modelo como tipo ideal, para posteriormente profundizar, en primer lugar, en los discursos sobre prácticas que se ajustan a aquel patrón y, en segundo lugar, en algunos elementos de tensión que surgen de su aplicación como instrumento de interpretación de la realidad. Finalmente, se presentan algunos aspectos de cómo las personas entrevistadas plasman en su discurso las continuidades y cambios del sistema. El ejercicio de reconstrucción en la memoria sirve para sostener que el modelo persiste a nivel simbólico, en valores y normas que im-

\footnotetext{
${ }^{1}$ Este artículo ha sido posible gracias al proyecto Arxiu de la memoria oral valenciana. Museu de la Paraula, que forma parte de las líneas de investigación del Servei d'Investigació en Etnologia i Cultura Tradicional (SIECT) del Museu Valencià d'Etnologia. El trabajo de campo del que proviene la información analizada se realizó en el marco de aquel proyecto con un convenio entre la Diputación de Valencia y la Universidad de Valencia, a través de dicho museo y del Departament de Sociologia i Antropologia Social. Agradezco los comentarios sobre una primera versión de este texto realizados en su día por todo el equipo y, en particular, a Jorge Cruz Orozco y Asunción García Zanón y la labor de campo de Pilar Luz, Pablo Monteagudo, Josep Miquel Bisbal, Raquel Ferrero, Jordi Giner y Arancha Grau.
} 
pregnan los discursos de los sujetos, a pesar de que muchas de las prácticas propias se han abandonado en un contexto de acusado cambio socieconómico.

Palabras clave: Parentesco, Familia troncal, Prácticas familiares, Memoria oral, Cambio social.

\section{SUMMARY}

This paper aims to study the reconstruction of the souche family model through the memory of the persons belonging to the last generation who has fully lived its operation, more or less directly, in Els Ports de Morella. A synthesis of this model is analyzed as an ideal type, in order to later analyse more thoroughly the discourses on practices adjusted to this pattern and, secondly, the elements of tension arising from its application as an instrument of interpretation of reality. Finally, we introduce some aspects on how the interviewed persons reflect, in their discourse, the continuities and changes of the system. The memory reconstruction exercised is used to support that the model persists in a symbolic level, in values and norms which pervade the individuals' discourses, in spite of the fact that many of such practices have been given up in a context with a marked socio-economical change.

Key words: Kinship, Souche Family, Family Practices, Oral Memory, Social Change.

\section{INTRODUCCIÓN}

En un trabajo clásico de la antropología del parentesco, Lisón (1976) trazaba un mapa de los tipos de familia existentes por entonces en España. Entre ellos se hallaba la familia troncal o souche, extendida por diversas zonas del norte peninsular, entre las que el autor citaba Els Ports de Morella. Lisón sostenía, entre otras cosas, que en el estudio de la familia era imprescindible "captar su increíble variedad y motivación empírica, sus significados y valores en perenne evolución” (1976: 51). Algo más de treinta años después, este artículo propone acercarse justamente a ese mismo modelo en aquella comarca valenciana, desde un punto de vista particular: el de la memoria de personas que forman parte de la última generación que ha tenido experiencia más o menos directa de la integridad de prácticas propias de ese sistema familiar.

El desarrollo del modelo troncal en Els Ports de Morella estuvo asociado, desde la Edad Media, a la forma de hábitat disperso conocida como mas, que vivió un fuerte impulso, en especial, a partir del siglo XVIII, con el auge de una ganadería y agricultura extensiva y una protoindustria textil que se iría consolidando hasta principios del siglo xx. Sin embargo, justamente desde este último periodo y hasta la década de los sesenta de ese siglo, ese hábitat entró en decadencia con una emigración hacia ciudades industriales del li- 
toral y, en menor medida, al interior de los pueblos de la comarca (Comas Dellà y Comas Cifre 2002; Pitarch 2003; Querol 1995). La continuidad de las antiguas unidades domésticas agrícolas quedaba, pues, en entredicho, y las nuevas condiciones socioeconómicas y demográficas ponían en duda la posibilidad de que se mantuviera el modelo familiar troncal. La finalidad de este texto es enfocar un aspecto particular de este posible mantenimiento: su reconstrucción en la memoria de quienes lo protagonizaron hasta mediados del siglo xx, entendiendo el modelo más como un referente teórico para la interpretación y el análisis socioantropológico que como un molde rígido que describe una realidad de forma apriorística.

La arquitectura de este trabajo responde justamente a este planteamiento. Después de hacer algunas precisiones teóricas y sobre la metodología y objetivos de la investigación que ha aportado la información analizada y una vez se hayan dado algunos detalles sobre la unidad de análisis, se presentará el modelo como tipo ideal a partir de diversos trabajos teóricos que lo han descrito pormenorizadamente. Posteriormente se profundizará en el caso estudiado para contrastar, por un lado, la memoria de prácticas que se ajustan a aquel patrón y, por otro, distintos elementos de tensión que surgen de su aplicación real como instrumento de interpretación de la realidad. En este sentido, se verá cómo, tanto en el diálogo entre entrevistador y entrevistado como en algunas de las descripciones de experiencias de las personas entrevistadas, los aspectos modélicos son representados en el discurso de forma particular, con algunos indicios de que dicho seguimiento ha sido difícil, en la práctica. Finalmente, un último apartado servirá para apuntar algunos aspectos de la forma como las personas entrevistadas plasman en su discurso las continuidades y cambios del sistema.

\section{LA MEMORIA ORAL COMO HERRAMIENTA: ALGUNAS CONSIDERACIONES TEÓRICAS}

La memoria como discurso producido y transmitido entre generaciones tiene la propiedad de ser capaz de seguir su curso, con una autonomía capaz de desprenderse de referentes factuales (Pujadas 2000). Y es que, mientras en la memoria todo modelo de relaciones e ideológico se puede representar como algo sometido a tensiones, pero mantenido, las excepciones al mismo fácilmente pueden quedar de algún modo silenciadas. Ello es algo particularmente interesante cuando los sujetos entrevistados han sido protagonistas de importantes cambios. Este contraste entre discurso en el recuerdo y prácticas es característico de las propias fuentes orales, pero en especial de la memoria. Justamente el valor de enfocar la realidad desde la memoria oral radica, en buena medida, en tomar el pulso a los cambios desde 
discursos que evidencian cómo el propio sujeto los experimenta y, sobre todo, como presenta el contraste con el pasado. En palabras de Thompson (2004: 15), de hecho, la memoria oral consiste en "la interpretación de la historia, las sociedades y las culturas en proceso de cambio a través de la escucha del registro de las memorias y experiencias de sus protagonistas".

Cuando tropos, figuras y episodios son compartidos por varios sujetos y transmitidos oralmente a otros, puede decirse que la memoria oral trasciende el nivel individual para anclarse en el colectivo. Entonces, la permanencia, la homogeneidad, la continuidad imaginada para la identidad del colectivo referente $-\mathrm{O}$, al menos, percibida en ella- se sostiene sobre esas mismas propiedades trasladadas al discurso de la memoria. En cierto modo, pues, existe un fino hilo que une memoria e identidad y su delicadeza deriva de la relación necesariamente conflictiva entre una representación - la identidad - en la que predominan continuidades y homogeneidad y una realidad - la sociedad - en la que se presentan discontinuidades y heterogeneidad que pueden poner en duda la claridad de aquella versión representada. Como numerosos autores han destacado ${ }^{2}$, la construcción de las identidades se sostiene - entre otras cosas - sobre la construcción de una continuidad entre pasado, presente y futuro, a través de narrativas de memoria que se fundamentan en recuerdos pero también en olvidos. Todo ejercicio de memoria, en realidad, es siempre selectivo (Candau 2002) y dicha selección se efectúa de acuerdo a los valores vigentes en el presente, lo que necesariamente conlleva olvidar unos recuerdos para quedarse con otros (Pereiro 2004). Paradójicamente, el recuerdo es imposible sin olvidar algo. A ello, además, hay que sumar una tendencia a la idealización del pasado, propia de la memoria cuando se construye en un presente que se contempla de forma crítica o pesimista por una u otra razón.

La memoria colectiva, como estableció hace ya tiempo Halbwachs (2004 [1950]), tiene sus marcos temporales (fechas, acontecimientos, estaciones...) y su marco espacial (edificaciones, lugares, objetos...) que soportan el carácter compartido de lo que distintos discursos contienen. Aún así, la construcción del recuerdo como algo colectivo depende del horizonte que se vislumbra más allá de él, en el futuro (Ricoeur 1999); es decir, cuando se

${ }^{2}$ La bibliografía que sostiene el papel clave de la memoria (y, con ella, del olvido) en la construcción de identidades colectivas es enorme. Baste recordar lo que apuntan sobre el papel de la memoria en dicho proceso autores como Pujadas (1993), Hobsbawm y Ranger (1988), Hamer (1984), Eriksen (1993), Mira (1984) o Cohen (1985). El papel del olvido es particularmente importante en casos en los que siguen en el recuerdo episodios de violencia, tal y como sugieren los trabajos de Todorov (2000), Frigolé (2001) o Malkki (1995) o varios de los trabajos que se recogen en Valcuende y Narotzky (2005). 
asume en cierta medida como herencia para un tiempo posterior. Los relatos a los que haremos referencia provienen de conversaciones mantenidas en un ejercicio más o menos consciente de narrar hoy el pasado —el "antes"- para un "mañana". En unos casos eso significa que se habla para las generaciones venideras (por lo general, de la propia familia) o, sencillamente, para que quede registrado aquello que podría perderse de no ser escuchadas las propias palabras. No en vano, antes de cada entrevista, todas las personas sabían que se les iba a entregar una copia del registro audiovisual de su conversación con la persona que las entrevistaba. A pesar de la situación de poder que suele adoptar esta última durante la conversación, es preciso tener en cuenta que — como de algún modo sugiere Bruner (2000) — relatos sobre el pasado, como los que aquí nos ocuparán, parten de esquemas culturales institucionalizados que permiten elaborarlos con un mínimo de sentido y, en realidad, las personas entrevistadas son quienes mejor conocen esos entresijos. La sensación de seguridad en sus posiciones ante entrevistadores que aparentemente desconocen aquellos esquemas subyacentes puede compensar de algún modo las condiciones dialógicas de cierta desigualdad en las que se construye el discurso.

Como han indicado Prat y colaboradores (2004), las historias de vida y biografías se recogen con un pretexto y su texto tiene sentido en relación a un contexto. En el caso que nos ocupa, el pretexto fue el proyecto Arxiu de la Memòria Oral Valenciana. Museu de la Paraula, destinado a entrevistar a sujetos que forman parte de una generación de ruptura, en la medida en que han vivido en primera persona la urbanización e industrialización de la Comunidad Valenciana y, con ello, las transformaciones de la sociedad tradicional. El propósito del proyecto es, a grandes rasgos, recuperar, estudiar y conservar la memoria como patrimonio de la Comunidad Valenciana, lo que se concretará en la elaboración de un gran archivo audiovisual de entrevistas que se podrá consultar online. Como se ha expuesto en otro lugar (Albert, Moncusí y Santamarina 2005; Moncusí 2006), el pretexto para las entrevistas es eminentemente patrimonial. El referente territorial de la activación patrimonial que trata de llevarse adelante es, en este caso, la Comunidad Valenciana considerada como un territorio formado por diversas comarcas. En este sentido, el discurso de las personas que hemos entrevistado adquiere el estatus de memoria colectiva desde el punto de vista de la construcción de un patrimonio compartido por todos los valencianos. Sin embargo, al mismo tiempo, desde el punto de vista epistemológico los distintos textos son colectivos en tanto que comparten varios aspectos que difícilmente contendrían si las personas que los formulan fueran habitantes de una comunidad de la Huerta o de una gran ciudad valenciana; elementos que permiten aprehender una determinada forma de representar la realidad. 
Thomas y Znaniecki (1958), Pujadas (2000), Thompson (1988) y Vallés (1999), entre otros, han destacado la gran utilidad de la memoria oral para la investigación social. Por un lado, ésta permite estudiar el cambio social por su carácter siempre retrospectivo y, según la técnica aplicada, longitudinal. Por otro lado, acudir a la memoria oral permite penetrar en el universo de las estructuras de mediación entre individuo y sociedad permitiendo ver múltiples aspectos de la vida cotidiana de los miembros de un grupo. Además de todo eso, la memoria oral da — como sugirió Thompson (1988)— "VOz a los sin vOZ" lo que le proporciona un notable valor humanista, puesto que se recupera al sujeto individual o colectivo como actor social protagonista. Cuando la memoria es eminentemente biográfica, permite, en definitiva, estudiar la estructura social no en términos mecanicistas, sino desde una dimensión subjetiva que le proporciona riqueza de matices y sentido (Ferraroti 1981).

Nuestra idea es visitar, justamente desde el punto de vista de la memoria oral, un asunto que desde el punto de vista ideológico, normativo y de organización social ha sido estructural en varias comunidades de montaña del norte de la Comunidad Valenciana. Recorreremos discursos de informantes que tienen en común haber residido durante más de sesenta años en localidades de la comarca valenciana de Els Ports, para ver un modelo familiar desde el punto de vista de sujetos que lo protagonizaron, que lo recrean entre olvidos, idealizaciones y, en general, de una forma que lo presenta como algo mucho más consistente de lo que probablemente fue en la práctica.

\section{APUNTES METODOLÓGICOS}

La información en la que se basa este artículo se obtuvo en una campaña de campo llevada a cabo en 2004, en Els Ports de Morella, durante la que se realizaron catorce entrevistas individuales, semidirigidas, de carácter biográfico, trece de las cuales se han utilizado aquî̉. Cada una de las personas tiene su propia trayectoria vital, que ofrece distintos matices a su discurso. En este sentido, la muestra recoge algunos aspectos que permiten discernir diversos perfiles. La estrategia que hemos seguido para abordar dichos discursos es ir siguiendo aspectos vinculados al modelo troncal, aún a riesgo de desdibujar algo la diversidad del conjunto de trayectorias. Para hacerse una mínima idea de ella, el lector puede acudir al cuadro anexo al final del texto, donde se detallan algunos datos sobre cada una de las per-

\footnotetext{
${ }^{3}$ Una de ellas no ha podido ser utilizada por problemas técnicos.
} 
sonas entrevistadas, identificadas con un código que permite ubicar las distintas citas en el conjunto ${ }^{4}$.

La selección de personas se realizó a partir de contactos con la administración municipal, centros de estudio, asociaciones e individuos particulares de las poblaciones de la comarca. De acuerdo con los criterios vigentes en aquel momento en el proyecto Arxiu de la Memòria Oral Valenciana. Museu de la Paraula, en el que se integraban las entrevistas realizadas, la muestra de informantes pretendía buscar una representatividad territorial, por medio de la selección de población de todas las localidades de la comarca, aunque ello conllevara que en alguna localidad se entrevistara a un solo sujeto. En cuanto a la variable de sexo, se intentó que la proporción fuera de la mitad para cada uno, aunque en la captación no se logró dicho equilibrio. Todas las personas eran nacidas antes de 1933 y habían pasado al menos tres cuartas partes de su vida en la comarca5. Por lo demás, con la muestra se buscaba una significación en base a actividad profesional y tipo de hábitat de residencia, de modo que prácticamente todas las personas o bien vivían o habían vivido en masos, o bien conocían la realidad de éstos a través de algún familiar.

La selección muestral por edad y el uso de información exclusivamente oral limitan considerablemente cualquier análisis en profundidad en un nivel intergeneracional, en cada caso. Por otra parte, esa selección no posibilita la generalización de las conclusiones de la investigación, lo que, de hecho, tampoco se ha pretendido. Este trabajo aspira a abrir vías a la reflexión sobre lo que queda del modelo troncal en la memoria de algunos de los que lo han conocido, más que a constatar el seguimiento o no del mismo, en la práctica. La técnica utilizada - entrevista semidirigida de orientación biográfica - tiene claras ventajas para lo que aquí se persigue. Como ha mostrado Vallés (1999), se privilegia el discurso de las personas entrevistadas, que se ve como algo rico y completo, y que surge con cierta imprevisión y flexibilidad, dado que se aplica un guión de forma abierta. El hecho de dar prioridad a las respuestas sobre las intervenciones del entrevistador es especialmente útil en este sentido. Se consigue, además, mantener cierta fidelidad a la perspectiva emic de la persona entrevistada quien, por otro lado, tiene la posibilidad de decidir qué considera reproducible en

\footnotetext{
${ }^{4}$ Los códigos usados son los utilizados por el Arxiu de la Memòria Oral Valenciana. Museu de la Paraula.

5 Para un conocimiento más detallado del proyecto Arxiu de la Memòria Oral Valenciana. Museu de la Paraula, véase García Zanón y Ferrero (2001) y Moncusí (2004 y 2006). Puede consultarse también la web http://www.museuvalenciaetnologia.es/ ficha_proyecto.html?cnt_id=1455.
} 
el contexto de la entrevista, decisión pertinente para analizar el contexto en el que lo dicho deviene significativo y en qué sentido (explicativo, normativo, descriptivo...).

La entrevista abierta resulta especialmente útil en una investigación como la que se llevó a cabo, aunque no siempre se lograra evitar condicionar el discurso del entrevistado. Las catorce entrevistas realizadas en la comarca de Els Ports fueron hechas con el referente del modelo troncal como algo predefinido, lo que conllevó una cierta insistencia en preguntas que se referían al mismo. Dicha obstinación contribuyó a generar intercambios dialécticos que constituyeron un fructífero contexto para que afloraran discursos sobre el modelo troncal, por parte de entrevistados cuya interpretación permite dar cuenta de la significación de aquel modelo como símbolo y patrón cultural normativo. Efectivamente, las descripciones y análisis de las personas entrevistadas remiten a categorías y esquemas culturales que pueden estar relacionados con el parentesco y la herencia, lo que en algunos casos conduce al modelo troncal.

Por lo que se refiere a la unidad de análisis de la investigación, la constituyen las poblaciones de Els Ports, comarca de montaña de la provincia de Castellón, en la frontera entre Aragón, Cataluña y la Comunidad Valenciana. En total la comarca tiene menos de 5200 habitantes, cifra que representa prácticamente una cuarta parte de la que tenía a mediados del siglo XVIII, época en la que el poblamiento disperso era todavía característico. En 1950 el 40\% de la población moraba en casas dispersas (masos), cifra que, según datos del INE, en 2003 había caído hasta el 9\%. La orografía abrupta, el suelo pedregoso y el invierno riguroso han condicionado una actividad agrícola centrada, de modo predominante, en el cultivo de trigo y plantas forrajeras. La actividad principal en Els Ports de Morella ha sido tradicionalmente la ganadería, especialmente de ovino, combinada - en menor medida- con agricultura extensiva. Esta actividad agropecuaria fundamentó el desarrollo de una proto-industria textil ya en la Edad Media y de varios establecimientos de tejido industrial, desde el siglo XVIII. La tecnología hidráulica favoreció que algunos de ellos adquirieran cierta envergadura, a finales del siglo XVIII, como es el caso de la Colonia textil Giner, en Morella, o la importante fábrica de Aznar en Villafranca, localidad de la vecina comarca del Maestrat. Pese a que ha quedado alguna pequeña industria textil, la actividad del sector decayó después de la Primera Guerra Mundial, ante el mayor dinamismo de zonas urbanas de llano, lo que conllevaría una emigración constante de población hacia ellas. Una tendencia demográfica negativa que ha continuado hasta hoy.

La dualidad entre masos y pueblos constituye una especificidad de la comarca, que se ha visto acompañada por un sistema de herencia asociado 
a la transmisión y mantenimiento de grandes propiedades de tierra integradas en aquellos núcleos aislados de poblamiento. Algo muy particular en el contexto de la Comunidad Valenciana, más bien caracterizada por la fragmentación de la propiedad de la tierra y la preponderancia de un sistema de herencia de carácter igualitario. Los cambios socioeconómicos y demográficos experimentados en la comarca configuran un contexto en el que es difícil sostener algunos aspectos asociados con la organización familiar troncal, tal y como se la conoce en términos antropológicos en otras zonas de la Península Ibérica. Sin embargo, persisten algunas prácticas y valores que se asocian a ella y, sobre todo, sigue presente en la memoria familiar y biográfica.

\section{EL MODELO TRONCAL COMO TIPO IDEAL}

En 1871, de acuerdo con una tendencia muy al uso en aquella época, Frederic Le Play establecía un esquema evolutivo de tipos de familia que incluía como el tipo más avanzado la que él denominó familia troncal. Como explica Bourdieu (2004), se trataba de un tipo contrapuesto al que el mismo autor denominó inestable, que identificaba como el surgido del Código Napoleónico. El modelo troncal se caracterizaba, a grandes rasgos, por la residencia de al menos tres generaciones de una familia en una misma casa y por un patrón de transmisión hereditaria que privilegiaba a varones primogénitos, otorgándoles la propiedad de la vivienda y, en su caso, de la mayor parte de tierras y ganado. Las ventajas del modelo quedan justificadas por el autor de este modo:

Al heredero, en compensación de pesadas obligaciones [este régimen sucesorio], le confiere la consideración que se le otorga al hogar y al taller de los antepasados; a los miembros que se casan fuera de la familia, les garantiza el apoyo de la casa troncal con las gracias de la independencia; a los que prefieren permanecer en el hogar paterno, les concede la tranquilidad del celibato con las alegrías de la familia; a todos les salvaguarda, hasta la vejez más extrema, la dicha de recuperar en el hogar paterno los recuerdos de la primera infancia [...]. Al instituir en cada generación un heredero, la familia troncal agrícola no sacrifica el interés de los segundones al del primogénito. Al contrario, condena a éste a renunciar durante toda su vida, a favor de sus hermanos, y luego de sus hijos, al fruto de su trabajo. La familia obtiene el sacrificio del interés material a través de una compensación de orden moral: la de la consideración vinculada a la posesión del hogar paterno (Le Play 1884: 36-37 y 114, citado en Bourdieu 2004: 132).

Le Play consideraba que el modelo, con sus valores morales positivos, se encontraba en riesgo de desaparición en Francia, por la intervención del Estado. Sin embargo, numerosos estudios demuestran la larga persistencia 
de prácticas propias de aquel modelo, pese a la implantación del nuevo código civil $^{6}$. El tipo ideal definido por Le Play ha sido utilizado con posterioridad en antropología e historia en un plano más analítico que normativo, abandonando cualquier consideración evolucionista o idealizadora de su lógica y prácticas?. Esta apropiación más rigurosa considera el patrón como un tipo ideal para interpretar prácticas, discursos y estrategias familiares desde una óptica sociocultural y, sobre todo, va más allá de una definición etic. Así, se ha sugerido que, en cierto modo, se puede hablar de un tipo de familia troncal en la práctica porque, entre otras cosas, se define desde una perspectiva emic sobre la familia y el parentesco. Es decir, se trata de un modelo normativo que condiciona prácticas sociales, entre las posibilidades y las necesidades de cada unidad doméstica (Bourdieu 1972). Los sujetos actúan con un referente ideal que después cumplen en la medida de sus posibilidades y expectativas.

Semejante planteamiento conlleva una aproximación dinámica a la realidad sociocultural que trasciende la aplicación objetivista, rígida y taxativa de un patrón estereotipado. A lo sumo, se pueden esbozar las líneas principales de un molde normativo que tienen como referente flexible los distintos sujetos, sabiendo de antemano que ello no conlleva su cumplimiento en todos los casos ni del mismo modo. Los puntales del sistema-tipo ${ }^{8}$ son las reglas de filiación, residencia, descendencia y herencia. En el primer caso, se trata de un sistema bilateral aunque con cierta tendencia patrilineal. Se reconoce la ascendencia independientemente del sexo, pero los derechos y deberes no se transmiten por igual a descendientes hombres y mujeres, ni tampoco independientemente del orden de su nacimiento. Por lo que se refiere a la residencia, es dependiente, aunque principalmente patri-virilocal. Los grupos domésticos se componen fundamentalmente por un heredero casado y algún hermano o hermana solteros, padres y abuelos, de modo que suelen incluir al menos tres generaciones.

En cuanto a la herencia, se transmite preferentemente indivisa a varones y primogénitos. Esto último se puede traducir en la modalidad de he-

${ }^{6}$ Bourdieu (2004) sintetiza varios de estos estudios para la zona del Bearn. Sobre dicha persistencia en otras áreas del Pirineo francés, véase Assier-Andrieu (1981 y 1986).

${ }^{7}$ Para seguir el hilo de este uso e identificar diversas tendencias en el estudio de la familia, véase Segalen (1992).

${ }^{8}$ La caracterización del modelo que presentamos a continuación se ha elaborado a partir de trabajos sobre distintos casos y que lo describen en general o en parte. Concretamente, hemos utilizado los textos de Barrera (1990 y 1994), Comas d'Argemir (1980 y 1994), De la Parte y Mas (2000), Estrada (1994), Estrada, Roigé y Beltrán (1993), Lisón (1980) y Mira (1980). 
redero universal, o por mejora. Es decir, o se da todo a un solo heredero o se le paga una parte adicional más de herencia que a sus hermanos/as. En tal caso se da una compensación a los no herederos con el pago de una legítima o de dote en bienes muebles, dinero o propiedades. El criterio es no fragmentar la propiedad de tierras, ganados o los bienes de los que disponga la familia. Si no hay descendencia se busca un ahijado, preferentemente entre sobrinos. Para las mujeres, la posibilidad de ser nombradas herederas queda limitada a la ausencia de descendientes varones.

En general, pues, se mantiene un criterio de edad y sexo a la hora de definir el lugar de los sujetos en la estructura familiar. Ello se traduce del mismo modo en las relaciones domésticas, de manera que la autoridad suele recaer en las personas de más edad y en los varones. Por otra parte, en el sistema troncal el grupo familiar prevalece sobre el individuo, lo que se manifiesta en el uso de un nombre de familia que define toda una estirpe y al que se asocian valores, prestigio e incluso una imagen de carácter familiar arraigada en cada individuo. En el modelo troncal, la casa es entendida como algo más que un edificio y propiedades familiares (terrenos y edificios anexos): se convierte en toda una institución social que conlleva una vertiente simbólica y alrededor de la cual se organiza la vida social y económica de los miembros de la unidad doméstica que, en general, se ven supeditados como individuos a las exigencias estructurales de la institución. En el interior de cada unidad se establece una jerarquía y se distribuyen derechos y obligaciones con respecto a bienes y personas, de acuerdo a la posición de cada individuo en relación con la transmisión del patrimonio.

La continuidad de la casa en cuanto a su prestigio y propiedades y, por tanto, la transmisión patrimonial, son posibles gracias a las estrategias matrimoniales y familiares. Se trata de un conjunto de maniobras que tienen por objeto la preservación del patrimonio como algo íntegro y que pasan fundamentalmente por intervenir en el matrimonio de los descendientes, condicionando la elección de cónyuge (si se produce) en función de las exigencias de la casa. Si bien no se trata exactamente de una determinación de la elección, se podría decir que la autoridad de los ascendentes condiciona las posibilidades de elección, mientras que la socialización de los hijos e hijas pone el resto.

Entre estas estrategias se encuentra la intervención directa en el casamiento de hijos/as, incluso con tratos escritos (capítulos) entre dos casas. Una de las alternativas preferentes para el caso de las hijas es el matrimonio con un heredero de otra casa. La homogamia es una tendencia bastante frecuente, pero no la boda entre herederos y herederas primogénitos/as. Los matrimonios encadenados, entre herederos y hermanas de dos casas, son una de las opciones para la reproducción de las casas, aunque no las 
únicas. Otras posibilidades son el levirato (matrimonio de una mujer viuda con el hermano de su difunto marido), el sororato (matrimonio de un hombre viudo con una hermana de su difunta esposa) o el celibato acompañado en algunos casos de la dedicación a sectores no agrarios (religioso o de profesión liberal).

El modelo está asociado al poblamiento disperso en forma de masos con ganadería y agricultura extensiva y se sigue mayormente cuando lo permiten las propiedades, y su seguimiento (cuando lo hay) es más escrupuloso en las casas que se encuentran en la cúspide de la estratificación social. En caso contrario, la herencia no acaba siendo indivisa o recae en hijos que deberían haber quedado excluidos de toda preeminencia, especialmente cuando varios herederos potenciales han abandonado las explotaciones domésticas por haber emigrado.

Aunque el sistema surge en unidades domésticas dedicadas al sector primario, la dedicación a tareas ajenas a él entra dentro de la línea de diversificación de la producción doméstica. Por otra parte, una empresa industrial o comercial puede convertirse en patrimonio familiar del mismo modo que un conjunto de propiedades agrícolas. En Cataluña se ha observado este hecho, junto con otro no menos significativo. Por un lado, McDonogh (1989) mostró en su estudio sobre las familias de la gran burguesía industrial barcelonesa una continuidad del modelo más allá de actividades agrícolas, tejida entre estrategias matrimoniales y adaptaciones jurídicas de empresas industriales que eran patrimonio familiar. Por otra parte, y en buena medida gracias al trabajo de folkloristas decimonónicos con pretensiones más o menos cientifistas, el propio modelo troncal y en particular la institución del bereu se convirtió en todo un referente simbólico para la identidad catalana, lo que contribuyó a su reificación como modelo ideológico que consagraba el paternalismo como ideal centrado en el trabajo, la propiedad y la autoridad patriarcal (Prat 1989). Dicho uso simbólico del modelo reificado se reflejó en la definición de familia catalana, caracterizada por el sistema troncal (Estrada 1989).

EL MODELO TRONCAL COMO REPRESENTACIÓN IDEOLÓGICA Y PATRÓN ORGANIZATIVO

El modelo troncal, tal y como se acaba de caracterizar, es un tipo ideal en tanto que modelo de análisis pero también configura un patrón ideológico que condiciona y estructura prácticas y discursos de actores sociales. Llegados a este punto, es posible un acercamiento a la información obtenida en las entrevistas realizadas en Els Ports para ver, en primer lugar, la memoria del seguimiento de prácticas de herencia, alianza y residencia, así 
como de los roles de género y generación. En segundo lugar, se podrá ver si existen puntos de tensión en el relato de las personas entrevistadas, que permitan entrever que el modelo tiene cierta flexibilidad y que es seguido de forma particular, en cada caso. Dichos aspectos surgen varias veces en un diálogo entre entrevistadores que rastrean prácticas y discursos modélicos, con cierta insistencia, y entrevistados que alguna vez contradicen y a menudo cumplen las expectativas de aquellos.

\section{Prácticas modélicas en la memoria}

tots entraen dins del límit de la raó i sabien lo que s'havie de fer (MO69: 28)

El término modelo familiar, remite a un esquema que permite organizar las relaciones familiares y, en general, las formas de producción y reproducción social vinculadas a la unidad doméstica y al mismo tiempo interpretar la realidad cotidiana. Es decir, que se trata al mismo tiempo de un patrón organizativo e ideológico que define, como dice el informante cuyas palabras abren este apartado, "el límite de la razón". La frase la pronunció un antiguo jornalero agrícola, con tres hermanas mayores, que se casó a finales de los años cuarenta con una hija del arrendatario de una de las grandes fincas de la comarca. Fue mejorado por sus padres, lo que conllevó que vivieran en casa de éstos. Siguió, pues, lo que se consideraba prescriptivo en su situación familiar. La frase concreta la formuló en un momento en el que el entrevistador le inquiría sobre los conflictos entre hermanos por la mejora. Si hacemos caso de lo que sugería el entrevistado, el propio modelo prevenía los conflictos por la actitud pragmática que acababan adoptando los implicados.

Podemos hablar de prácticas que, tal y como son presentadas en el discurso, no sobrepasan este límite por lo que se podrian calificar como modélicas. Por lo que respecta a la residencia, por ejemplo, solía ser patrivirilocal, de acuerdo con un principio no escrito que describe muy gráficamente una molinera de Palanques, cuando explica cómo las mujeres, una vez casadas, a menudo pasaban a residir en casa de los padres del novio: "el que té un fill, fa el compte que té una filla. Al casar-se ja tenia una filla, enca que estigueren sempre lutxant" (MO-74:11). La nuera, pues, era recibida como una nueva hija y se sumaba a un grupo de residentes que solía agrupar a familiares de tres generaciones. Así lo recuerdan, de hecho, varias de las personas entrevistadas. Un caso paradigmático es el de un informante que explica así como residía en la casa en la que sus padres establecieron una carnicería: 
En cualquier casa había diez personas. Cuando yo me casé, estaban ocho hermanos en mi casa, mi madre nueve, bueno, los nueve hermanos, mi madre diez, y esta mujer, mi mujer que vino allí, once. Y en después ya teníamos dos hijos, los dos hijos, que después tuvo otro y se murió, jtrece en la mesa! [...] (MO70: 14-15).

Hay, además, un consenso entre las personas entrevistadas en que dentro del grupo familiar se daría una preeminencia de las personas de más edad y particularmente de los hombres. Así lo expresa con claridad el mismo informante, cuando se le pregunta sobre el papel de sus abuelos en el hogar:

Ah! pues generalmente el abuelo [era el amo], se respetaba mucho, aunque los bienes fueran ya del hijo, se respetaba mucho la jerarquía, generalmente si el abuelo estaba en esto [...] Esto pasa ahora, que algunas veces aún me meto yo en cosas que no me había de meter [...] porque los bienes son del hijo y... ya hace que lo arreglé yo esto, y... sí [...] Bueno, siempre ha sido eso el hijo, pero el abuelo se ha respetao mucho eso que tiene experiencia y la jerarquía y el... sí, ahora no se respeta tanto, ahora se ha cambiao todo mucho pero eso sí mientras mandaba, mientras estaba el abuelo aunque los bienes fueran del hijo y tal pero el abuelo aún pintaba algo y... se respetaba mucho su criterio y, si estaba en sí.. (MO70: 68).

La misma persona expone cómo la situación de la abuela también había sido preeminente sobre quienes eran sus hijos. De hecho, según el mismo informante, ella fue quien propuso que su hijo se casará con la criada, a principios del siglo XVIII.

En cuanto a la herencia, en varias de las entrevistas realizadas se recuerdan casos de mejora a un hijo como futuro heredero, en la propia familia. El mantenimiento de la mayor parte del patrimonio en manos de un solo hijo (el varón mayor) lo justificaba de este modo un agricultor de un mas de la localidad de Forcall, el mayor hermano varón de seis:

Ah perquè mira, és que aixina ja no seria mas ni serie res ja, si escomençaen a fer trossos, com és terreno mísero això, que no és cap terreno ric com per ahí baix, com per València i per ahí, això és montanya, això és terreno pobre i no, i claro, i el que se quedae allí pues se fee càrrec de cuidar als agüelos tamé mentre visqueren, com entonces la gent vella no cobrae com ara, no cobraen de la seguridad social ni tenien cap aseguro ni res, pues el que dixaen amillorat allí, li dien l'amillorat el que es quedae allí, pues se fee càrrec de cuidar els agüelos mentres visquere i estaen allí en ells i avant, hasta que se morien (MO80: 03).

La mayor parte de terrenos de la propiedad (la mitad o tres terceras partes, según los casos) y la casa se incorporaban a un patrimonio a cuya transmisión iba asociado el deber de cuidar de los ascendientes familiares. Así era, por lo menos, en teoría, puesto que la misma persona expone que en su caso hubo un reparto equitativo de la herencia entre los distintos hi- 
jos e hijas, aunque con cierta preeminencia para con sus dos hermanastras (hijas de su padre y una segunda mujer). Los cuatro hermanos que vivían cuando sus padres fallecieron se quedaron con la propiedad del mas, en el que finalmente ninguno de ellos residió.

El hecho de que la herencia debiera recaer sobre un varón se asociaba con la creencia en las mayores capacidades masculinas en cuanto a la dirección de la explotación y el trabajo de la tierra. El hijo que permanecía en la unidad doméstica se encontraba entonces en una situación ventajosa, aunque no fácil. Así lo recuerda, por ejemplo, un ganadero y agricultor nacido en 1918, cuyo padre y abuelo habían sido mejorados:

Generalmente el hijo mayor se quedaba en casa y se le daba la mitad de los bienes o esto, y después la faena de él era pa pagarsele a los otros, si les asignaban... [...] Y pa dar esas pesetas. El que estaba en casa se veía con la horca al cuello [...] Pero vaya siempre era rico, el de casa [...] porque aunque le costara, que a veces le costaba mucho trabajo, a lo mejor se casaba con otra chica que tenía dinero, y con aquello le ayudaba mucho pa pagar a los hermanos. Pero, si no había muchos que se veían muchos apuros pa pagar a los hermanos. Porque los duros costaban mucho de hacer (MO70: 20-21).

En varias entrevistas vemos también que la mejora conllevaba el pago de una compensación a los no herederos (legítima). Ocurrió, por ejemplo, en los siguientes casos, de primogénito heredero y de hermana de un mejorado, respectivamente:

Ahí se reunien els pares en els fills i dien: "qui és el que, qui serà el que mos cuidarà a mosatros?" Pues jo. Vale, pues tu has de tindre açò, i vosatros tindreu una llegítima de la herència. Entens? O sea de que el que se quedae que no cuidae als pares, aquells tenien una llegítima de la herència que hi havie, cases u terres o lo que havie (MO75: 2).

Es el hereu, en la condició que ell ha de donar a les germanes tant a cada una, lo que fore, i si no ho cumplie, pos perdie ell lo que, perdie lo d'ell, i se quedave només en la llegítima que no se li pot llevar a cap fill... la llegítima (MO74: 3).

El derecho a la legítima no era exclusivo de los hijos e hijas, sino que también se podía hacer extensivo a las viudas, como expone un antiguo masover, recordando el caso de su padre y la legítima que tuvieron que sufragar los hijos a su segunda esposa, al morir aquel:

L'amo ere l'home. Si ell, si faltae ell, pues ell si no feen un testament o això, ella [la vídua] teni un dret de viudatge, que no li'l podien llevar [...] una llegítima. Segons els fills que n'hi havie ere més gran o més menuda. Però, si feen testament, pues li deixae un passament pa' que ella puguere viure, i lo atre pues s'ho partien [...] En morir-se mon pare, pos ella [la madrastra] es va quedar en blanc, perquè com la finca ere això, pos eixa dona tenie una legítima [...] Van tindre que avaluar els animals, van tindre que avaluar-ho tot [...] Perquè jo en aquells temps, 
que això, ja me vaig quedar a la voreta de trenta mil duros en deutes, que havie de donar-li a la meua madrastra [...] per la llegítima. I set cafissos de blat tos los anys [...] Perquè jo tenia allí el problema, que eixa dona [...] si haguérem anat al mal o això [...] m'haguere pogut marcar una llegítima, dins la finca, a on li haguere donat la gana [...] Ella tenie una xica del primer home, que del mas no tenie res [...] Pos a vore si pot arreplegar algo pa' la xica. Me pareix correcte. No és que la critico. Me pareix correcte (MO72: 33-34).

De hecho, alguna de las personas entrevistadas recuerda casos en los que la carencia de heredero se suplió con ahijamiento:

Los traían de Barcelona, entonces le llamaban eh... adoctados [adoptados] no, les llamaban bordes: "Fulano es borde", "Fulano es borde" [...] Siempre ha habido, los matrimonios que no tenían hijos y algunos hasta teniendo, porque primeros los traían porque pagaban, pagaban un tanto, pagaban 50 céntimos diarios, pero era mucho, por darles de mamar [...] y a los dos años había que volverlos y muchos no tenían coraje de volverlos y aunque ya tuvieron 2 o 3 más no los volvían [...] Se les moría un niño, como se morían tantos, y algunas por ganar dinero que estaba tan escaso traía uno de esos, y ganaban 50 céntimos diarios por darle de mamar pero luego al volverlo pues no tenían coraje y se lo quedaban y entonces sí que había que adoctarlo [adoptarlo] y señalarle un dote de 1000 pesetas, esto te hablo de cuando yo era niño [...] Porque se lo quedaba en casa [...] Y después heredaba como todos (MO-70: 64).

El mismo informante expone, en referencia al caso de su mujer y sus cuñadas, cómo el matrimonio conllevaba, cuando era posible, el pago de una dote que, entre otras cosas, servía a modo de seguro para la mujer que se casaba:

Pos mira, mil pesetas a cada una de dote, las habían asignao. ¡Mil pesetas! de aquellos tiempos que eran mayores que nosotros [...] En aquellos tiempos mil pesetas por escrito, el día que se casaban mil pesetas. Y después si quedaba la legítima que fuera o... o cuando morían los padres se partían las tierras, o lo que sea [...] Y algunos dos mil, pero ya había algunos que les daban cinco mil. Las casas ricas ya les daban cinco mil pesetas el dia que se casaban, que era el dote [...] Pero de esas había pocas. [...] Antes de nacer yo, ya había algunas que les habían dao cinco mil pesetas. Pero de esas el uno por cien [...]Lo normal eran dos mil pesetas, de dote. Tres mil (MO70: 26-29).

Un caso similar lo expone una mujer cuyo marido heredó un mas, por ser el varón de mayor edad:

Fija't ací a la família del meu home, davant hi havie quatre xiques i, i no [...] Les xiques es donaen en diners lo que fore i, vamos lo que fore, la part corresponent que els tocae, de dot, però la finca se quedae pa' pa' l'hereu, és lo que s'estilae (MO71: 28). 
Por lo que se refiere a las estrategias matrimoniales, en varias entrevistas se recuerda que la elección matrimonial, cuando se producía, estaba bastante controlada por la familia de orientación. Aunque en ningún caso se hace referencia a los propios familiares, se explica que en la generación precedente a la de nuestros informantes, había personas dedicadas explícitamente a "arreglar" matrimonios:

Hi havie unes dones o uns homes, però normalment eren dones. Que arreglaen als pobles, arreglaen els matrimonis. Ui, casamenters [...] la dona que sigue, pues di: "pst, ie, tu has de voler a fulana i tu a fulano". Ala, poseu-se, que si, pues no, i es liaen [...] Alguns li donaen una barcella de blat, altres li donaen un agraïment o el que fóre, i avant (MO75: 41).

Entonces iban muchos hombres con una caballería por las masías a recoger los huevos de las gallinas y a vender cosas [...] Estas gentes que iban de masía en masía, eran los que arreglaban más casamientos. Porque [...] una masía que había muchas chicas. "iAh! pues tu a la masía tal..." [...] que ahí buscan una chica, una masía que, casica mascarada que se decía. Una casa mascarada se decía a una casa, pues bueno, que había bienes [...] Pues esa gente, eran las que más arreglaban los casamientos cuando antes que yo, anteriormente a lo mío. Cuando lo mío alguno, pero pocos ya. [...] Había casas que había tres chicas o cuatro, pues todas las colocaba el mismo. Por aquí, una aquí, otra allá, las masías... casicas buenas [...] Ahora aunque sea uno del jornal vive muy bien. Pero de tener un algo a no tener nada había una diferencia muy regrande pa' vivir [...] Si no tiene bienes, hay que buscalos. Pa' comer. De no tener nada, a tener un poco [...] pues hay mucha diferencia (MO70: 23-25).

Sobre los motivos que llevaban a estos arreglos, en las entrevistas aparecen dos posibilidades. De un lado, la del beneficio económico directo, por alianza entre familias:

Pels diners, la majoria. Dels pobres eren di-[ners], però no, també se'n casave alguno. Per les famílies els que t'estic dient. Però la majoria dels rics que diem, que díem entonces, pues per les herències. Per no desfer les herències, u, diu: "xe, me caso jo amb eixa xica", o "me caso jo amb eixe xic, que tenen moltes finques, i tenen alguna perreta" (MO78: 5-6).

Como los casamientos se hacían así de conveniencia, pues había mucha costumbre, como vosotros si sois matrimonio, un sobrino tuyo y una sobrina de él, casalos [...] Y los bienes pa' ellos. Sí. De esto se hacía en muchas masías. En muchas casas [...] Había mucha costumbre esto. Un sobrino de cada conyugue se casaban, y mira, les daban los bienes. Aquí mismo, mira, en cualquier masía. Te diría veinticinco. Ese era la costumbre que había más. Si no tenían hijos (MO70: 22-23).

La segunda posibilidad se formula como una necesidad genérica de encontrar pareja para cumplir funciones asociadas a la producción en la unidad doméstica:

Diuen: "Pos mira, en tal puesto n'hi ha una viuda". "En tal puesto n'hi ha un viudo". "Pos a vore quina forma mos entrevistem i avant." Això ja ere [...] com si ja 
anigueres a comprar un corder [...] Ara no ho sé, però si no, entonces no crec que sigue amor. Ere necessitat [...] Necessitat! Pa l'home i pa' la dona [...] Si planxar la camisa, que si llavat, que si te, te, t'has de cosir un surcit als calcetins... xe! Arreu. I la dona, una dona que sigue de l'agricultura, si se li ha mort l'home, com te que anar ella a llaurar, a segar, a donar minjar als gorrinos, a... això ho ha de fer un home. No ho pot fer-ho ella. Pos això són necessitats. Pa' uno i pa' l'atre. Solució? Pos no n'hi ha més que eixa. I claro, un viudo no..., lo que més haguere vullgut és trobar a una fadrina. Però ja no anaen a tocar una fadrina. Sabien que havien d'anar a tocar... (MO72: 16).

Una vez llevado a cabo el matrimonio, su papel de alianza entre familias podía salvaguardarse en caso de defunción de uno de los cónyuges, para lo que se elegía a una hermana o hermano soltero del difunto en cuestión. Es lo que, como ya hemos visto, en terminología antropológica se conoce como levirato y sororato. La primera opción es la que se recuerda en el siguiente caso:

No se casaba porque era sordo [...] Y estaba aún en la casa sin casarse [...] Ese era cuñao [...] Y se casó con el cuñao, y mira pues un casamiento de conveniencia. Por tener un hombre en casa, el sordo había de estar allí, y ella también, porque estaba la cosa atada así, y así vivieron [...] Yo mi abuela, era mi abuela. Y mi abuelo, era mi abuelo, que no era nada, pero que ya mos-... Él nos quería con delirio y nosotros a él, tal como iban subiendo los nieticos [...] Si mi abuela no se hubiese casao con este señor [...] pues allí hubiese estao viuda con el hijo y se podía haber casao con otro. Pero allí otro no entraba con aquellas condiciones. Porque pa' entrar sin tener ningunos bienes. Comprenderás ¿̇no? Mi abuela se podía haber casao con otro señor. Ya era muy, también era muy mayor, ya. De treinta y tantos años [...] Trenta años, u más, cuando se quedó viuda. Y se podía haber casao con otro señor o, quedarse viuda toda la vida con el hijo [...] ¡Oi! ¡Entonces había una disciplina! [...] $\mathrm{Pa}$ casarse mi abuela con otro, era difícil porque los bienes eran ya de mis padres. Y pa casarse uno allí con, $p a$ estar como de criao porque, no podía disponer de esos bienes. Sólo eran usufructarios [...] Y por eso se casó con el cuñao, y así pues mira, siguió la casa lo mismo que antes (MO70: 13).

El siguiente ejemplo corresponde al sororato:

Com que vivíem juntament en els meus agüelos pues, els meus pares vivien juntament en ells, perquè portaen totes les terres i ho portaen tot junt, treballaen tot junt. Entonses, al cap d'un any que s'havia mort ma mare, els meus agüelos van dir-li: "per què no et cases en l'altra germana?", que ja ere la padrina meua. I li va parèixer bé [...] I vam tornar a seguir tota la família com havíem estat antes. I entonses fills de ma mare que diguéssim del primer matrimoni ja ne vam ser-ne quatre, quatre que no vivia més que jo al final, i eixa germaneta que va quedà d'un mes, però a l'any també va morí eixa xiqueta [...] I entonses va ser quan el meus agüelos li van dir: "per què no et cases en $\mathrm{M}^{\mathrm{a}}$ Gràcia?", que li dien a la meua segona mare, i ja ere padrina meua. I ho van acordar aixina, i a l'any pos se van casar $[\ldots]$ 


\section{Escolte'm Maria Gràcia, i on quedava, on quedava l'amor en eixos...?}

És que entonses no ere amor, entonses eren arreglos, però com que ja estaen tots vivint junts, com convivíem junts ja es coneixíem tots i vivien i bé, s'entenien, s'entenien, baix del manto dels agüelos vells [...] Que eren els que manaen. M'agüelo va tindre un cas que als 30 anys ell se va quedà del reuma, de la ciàtica no va poder treballar [...], va quedar-li una cama malament, li van fer tots els medicaments que havien entonses bé, no li podien traure el reuma de cap manera i en lo únic que va traure una mica d'alivio va ser anant als banys [...] $\mathrm{Pa}^{\prime}$ treballar el camp en molta faena ell ja no podie, necessitae el gendre a casa pa' fer anar la casa, i vivien junts (MO79: 1-2).

Es interesante constatar el contraste entre esta visión estratégica del matrimonio y una noción romántica que se encuentra detrás de la pregunta del entrevistador. En la aplicación del modelo troncal, el establecimiento de relaciones matrimoniales fácilmente se podía mover entre el amor y el interés, en el sentido de cumplir con expectativas estructurales e institucionales mientras, al mismo tiempo, cabría la posibilidad de desarrollar un particular afecto por el o la nuevo/a acompañante en la travesía; sería, de hecho, el espacio reconocido institucionalmente para ese afecto (Estrada, Roigé y Beltrán 1993). La estabilidad de las estructuras de parentesco y, en particular, el valor del matrimonio se han encontrado detrás de una noción de amor "hasta que la muerte nos separe". En la sociedad de la modernidad avanzada, la individualización es coherente con cierta debilitación de aquel valor y estabilidad, con mayor espacio para los proyectos individuales y hasta para una redefinición de la noción de amor (Bauman 2005). De hecho, a diferencia de la noción premoderna de amor, la idea romántica, surgida a finales del siglo XVIII, ya introducía el amor en la trayectoria biográfica individual como si de un permanente proyecto en curso pudiera tratarse; una odisea que, lejos de estar sujeta siempre a un apasionamiento completamente irracional, podría ser controlada por cada individuo de forma racional y reflexiva, dentro de las posibilidades institucionales que se le ofrecían (Giddens 1992). El amor, así entendido, puede hacer colisionar los intereses familiares y la libertad individual (Beck y Beck-Gernsheim 1995). Así se puede entender la tensión que se expresa en las citas anteriores, entre dos maneras distintas de entender el amor y el matrimonio que no son ajenas al diferente papel de las presiones institucionales, familiares o la elección individual, en la configuración de las decisiones que se toman y la forma en que se asumen. La institución familiar, en los casos descritos, era un marco clave de esa toma de decisiones y de esa asunción, restringiendo enormemente —al menos a priori- un margen individual de decisión que, a juzgar por nuestras entrevistas, difícilmente se cuestionaba.

Las estrategias matrimoniales se podían combinar con el celibato de otros 
miembros de la unidad doméstica. Es lo que ocurrió, precisamente, con el hermano y la hermana de la segunda esposa citada en el caso anterior. Ambos permanecieron solteros y se dedicaron a la religión, una como monja y otro como sacerdote. En otra entrevista se hace mención genérica de solteros que "solían estar toda la vida, hasta que morían con los padres" (MO70: 63), aunque se resalta que se trataba de pocos casos.

Finalmente, al hilo de las prácticas modélicas se pueden observar dos aspectos simbólicos. En primer lugar, el valor atribuido a la casa propia o a la ajena. Una de las personas entrevistadas - heredera de una casa de más de trescientos años, y a la que incluso ha dedicado poemas- se mostraba orgullosa de su casa, no tanto como edificio, sino como símbolo familiar:

Jo a esta casa li tinc voluntat. Perquè és una cosa que és d'anys i anys (MO68: 3).

Ese mismo valor asignado por el paso de los años puede servir, simbólicamente, para estimar el prestigio de una casa ajena, como explica un informante cuando trata de las razones para que se produjeran arreglos matrimoniales:

Antes dien que a ser possible t'havies de casar en una xica que tinguera la casa el fumeral [...] Si no estae el fumeral, no hi havie res, si estae el fumeral, tenie algo (de menjar) [...] perquè vol dir que d'estar negre és que una casa té solera, eh? (MO75: 42).

El segundo aspecto simbólico que aparece en las entrevistas es el nombre de casa que acaba identificando a cada familia:

Ací les cases pues normalment tenim cada casa un mote (MO-75:12).

Se trata, de todos modos, de una referencia puntual y prácticamente circunscrita al caso de los masos.

\section{Elementos de tensión del modelo, en la memoria}

El recuerdo de los entrevistados sobre el modelo troncal presenta algunas tensiones a las que éste se ve sometido. Se trata de aspectos que contribuyen a modelar una memoria personal de cada sujeto, en lo que es la experiencia de aquellas prácticas que hemos definido como modélicas y al mismo tiempo de elementos que surgen a partir de preguntas de entrevistados que muestran curiosidad por determinados aspectos.

Un primer elemento es la propiedad de la casa y la residencia. A una pregunta hecha al respecto por la persona entrevistadora, una de las mujeres entrevistadas respondió que "el meu germà s'havie de quedar a casa i 
nosaltres havíem de marxar, quan te casares havies de marxar i avant, i ja ho sabies això" (MO-74: 16). La posible tensión queda, en este caso, superada por esa voluntad de seguir, no sin cierta resignación. La misma persona responde al interrogante sobre porqué se debe dar la mayor parte de la herencia a uno de los descendientes con una frase contundente: "era el costum" (MO 74: 4).

En cualquier caso, siempre hay espacio para variaciones más o menos inesperadas. Así, cuando en una de las entrevistas se preguntó si siempre eran herederos los hombres y, a poder ser, los de más edad, se respondió que por regla general sí, aunque si:

No congeniaen los genits en lo majó i el pare i entrave el segon, eh?, o a lo millor, o heredera també, comprens? Igual entrae, igual entrae per part d'home que per part de dona (MO-69: 8).

N'hi havia puestos que a la xica, segons, això segons lo que els pares volien [...] per un regular si n'hi havie un fill millor perquè pa treballar la terra sempre, el fill més, un home més que una dona, per un regular (MO-74: 11).

Otro aspecto que ponía en tensión el modelo, según la memoria de los entrevistados, era la tirantez de la relación entre suegra y nuera, que se presenta como difícilmente resuelta e incluso meramente soportada:

Sempre estava la guerra, perquè la nora i els sogres no s'avenien mai, a cap puesto, entonces. Però tenien que passar per ahí, perquè sinó pos no se podie viure (MO-74: 10).

Una tensión parecida surge alrededor de otras relaciones intergeneracionales. En los siguientes ejemplos, el entrevistador se interesa por la autoridad en la unidad doméstica donde:

Sempre, normalment va manar el major [...] El major de la família és el que manae, i sempre se va respetar al pare i a la mare (MO75: 16).

El sogre, jo era criat allí, jo estava apegat [...] Jo vaig anar, l'amo del mas era un altre (MO-81: 43).

Este tipo de tensiones surgen en el relato cuando se habla de la aplicación de las estrategias matrimoniales. Es en este aspecto y en el de la herencia en los que más a menudo se prodigan los entrevistadores en preguntar qué les parecía lo que sucedía a las personas entrevistadas u a otros. La respuesta, en este caso, sigue un patrón parecido a las anteriores:

Als pares de sa mare, per exemple, els va pareixer bé que son pare es tornara a casar?

Sí, sí, sí! En això no hi havie... Entonses, entonses casi que ere, que ere, no sé si ere obligat, o ja no sé, però es casaen casi tots (MO72: 15). 
La cuestión de la herencia suscita interrogantes parecidos entre los entrevistadores:

A la seua dona $i$ a les germanes els pareixia bé que per ser xiques els tocara una casa a partir $i$ al atres dos per ser xics?

Ui pos mira, a tots los puestos passae igual, tots igual no podien ser, sempre n'hi havia que n'ixie més, els hòmens sempre estaven més ben mirats [riu] no veus que, mira la meua sogra sempre: "ui els xics, els xics," els homes sobretot, les xiques, les xiques sempre paeix que no, no es guanyaen res, sempre paeix que no [...] Això, home una vegà els tenie pues, com tots què havie de fer, però vull dir que sempre esten més ben mirats els xics que les xiques [riu] (MO8: 30).

Vosté desde xicoteta ja sabia que l'herència anava a ser per al seu germà. Sí.

I a vosté això que li semblava, li semblava bé?

Oi pues no res! Que hai de fer? Ja ho sabia! Això ja ho sabien a les cases, el meu germà s'havie de quedar a casa i nosaltres havíem de marxar, quan te casares havies de marxar i avant, i ja ho sabies això (MO-74: 15).

En el último caso aparece la expresión "i avant", muy generalizada en varias comarcas de Castellón como muletilla sin valor semántico que, sin embargo, es una buena metáfora de una determinación última que indica que no se duda del modelo, pese a las tensiones que surgen en la realidad y que afloran en el diálogo. Es, de hecho, un tropo que ilustra perfectamente cómo el modelo opera en la memoria de los informantes. El empeño de los entrevistadores en desentrañar elementos de tensión y, especialmente, en intentar aprehender la postura de los sujetos ante los mismos obtiene como respuesta relatos sobre cómo se seguía adelante asumiendo el modelo como patrón ideológico y normativo cuyos imperativos era difícil esquivar.

\section{CAMBIOS Y CONTINUIDADES EN LAS PRÁCTICAS FAMILIARES}

Lo visto hasta aquí se refiere a la memoria del sistema. Sin embargo, como marco normativo, su aplicación al presente deja entrever múltiples cambios y una continuidad más bien simbólica. Por ejemplo, mientras la mejora había sido para la generación de las personas entrevistadas una realidad institucionalizada, no ocurre así con sus descendientes:

Ara jo, jo i mon germà ja no ho hem fet aixina [...] No res d'amillorats. Els dos iguals [...] tot lo que traem és pa'ls dos i punto. I si un dia o atre, no el podem comprar ni la meua filla ni els meus nebots, no mos podem comprar d'uns a l'atre, sempre els dic una cosa: "Que no el partisquen! Que el venguen sancer! I els diners són més bons de partir". Però la finca que no la estrossen (MO72: 28).

La tierra ha pasado a ser medida más por su valor de cambio que por el de uso. De hecho, la propia continuidad de las unidades domésticas se 
ve afectada por el peso estructural de la emigración. La capital comarcal -Morella- tiene varios núcleos reconocidos por el Nomeclàtor cuya población no supera los ciento cincuenta habitantes e incluso no llega a diez habitantes. El descenso de población, que en algún caso llega al abandono de algunas zonas residenciales, y en el caso que nos ocupa especialmente de masos, es conocido en otras zonas del interior valenciano. Se trata de una crisis demográfica entre cuyas causas socioeconómicas destaca la no continuidad de la agricultura tradicional, que en zonas de montaña y secano como Els Ports, pierde competitividad ante otras mejor comunicadas, con implantación de regadío - y mayor facilidad para implantarlo- y en las que la mecanización resulta más rentable a corto y medio plazo. Una agricultura moderna e intensiva a la que hay que sumar la gran importancia de oferta de trabajo en otros sectores surgida durante los años de desarrollismo español lejos de la comarca y la gran diferencia entre los servicios disponibles en aquellas zonas en comparación con la propia. Pese a que se mantiene la ganadería como actividad principal, con la importante aportación del ganado porcino y avícola, y a pesar de las aportaciones del naciente sector de turismo rural, la atracción de población hacia otras zonas no se ha visto interrumpida (Mira 1978; Querol 1995; Rosselló 1995). Todo cambio social conlleva transformaciones y continuidades (Comas d'Argemir y Contreras 1990) y el que ha operado sobre la primera mitad del siglo xx en Els Ports no es una excepción. Algunos estudios efectuados sobre zonas donde imperaba el sistema familiar troncal, muestran que se producen dificultades para la reproducción del sistema.

En cuanto a las transformaciones, las unidades domésticas difícilmente pueden mantener su condición de unidad de consumo y de producción. La herencia indivisa se deja de aplicar — a excepción de la propiedad de la casa, entendida como edificio- cuando se da una dedicación de los descendientes a actividades que no precisan de una explotación agropecuaria de cierto tamaño. Las estrategias de herencia y matrimonio acaban quedando también en un segundo plano, en un contexto en el que el patrimonio de la casa pierde valor productivo y en el que operan valores asociados a la salarización. En ocasiones tampoco se puede sostener el modelo residencial de familia extensa en la comarca.

Por lo que se refiere a las continuidades, se mantiene en muchos casos una estrategia productiva de diversificación económica. Por otra parte, se pueden establecer formas de coresidencia que permiten reconstruir la unidad residencial extensa de la casa, básicamente con la incorporación temporal o definitiva de uno de los abuelos al grupo residencial de uno de sus descendientes, a menudo después de enviudar el progenitor/a. Otro aspecto de continuidad es el mantenimiento de las relaciones de parentesco y del 
intercambio de bienes, servicios y prestaciones personales que se sostienen a través de visitas, llamadas de teléfono o actividades comunes. Esto último contribuye a reforzar una imagen de continuidad en el tiempo en forma de memoria genealógica, algo que adquiere un valor especial en un mundo moderno continuamente cambiante. Las relaciones intergeneracionales, pues, siguen siendo fundamentales, aunque gana peso la autonomía residencial de los descendientes. Por último se mantienen aspectos simbólicos vinculados al modelo troncal, por ejemplo, la pertenencia a una casa como vía para ser reconocido como miembro de una comunidad y para constituir la propia identidad personal y social (De la Parte y Mas 2004; Pujadas, Soronellas y Casals 2007; Roigé 1997 y 2002; Soronellas 2002).

En el caso de Els Ports, la crisis demográfica y los cambios socioeconómicos han afectado a los cimientos mismos de la familia extensa. En primer lugar, se rompe —entre la generación de los sujetos entrevistados y la de sus descendientes - la posibilidad de que se mantengan núcleos residenciales numerosos:

Home, han canviat perquè no se pot actuar com entonses, perquè ara jo si tinguera los dos fills aquí, què farien aquí en mi? No veus que no n'hi han mitjos de vida ara, bueno, mitjos de vida, n'hi ha que sí que estan, mira, tots mos vam fer unes granjes, és dir que de l'agricultura vam passar a l'avicultura, no? I claro pos, pos entonses les terres ja es van deixar avorrides perquè no interessave treballar-les. I mira, aixina s'ha anat transcorrent la vida, eh? (MO69: 19).

Paralelamente, parece que el cuidado de los ancianos no queda tanto en manos directamente de sus descendientes (estén o no mejorados):

Ara estan les residències. Que els auelos fan gràcia a molt poquets fills (MO75: 37).

En este sentido, uno de los cambios percibidos con más claridad por las personas entrevistadas radica en las relaciones intergeneracionales. Las estrategias matrimoniales se habían visto marcadas, según recordaban los informantes, por decisiones verticales de la generación ascendiente, sobre sus hijos, con arreglos de diversa índole. Ello contrasta con una situación en la que aquellos hijos, cuando son ahora padres y abuelos, perciben en sus descendientes una mayor autonomía y poder:

La majoria cedien [els fills respecte dels matrimonis concertats], perquè entonces no podies estar [...] Això passave este, els fills estan adominats dels pares, entonces. I avui en dia és al contrari, vull dir jo que ha canviat tot (MO78: 5).

De hecho, ninguna de las personas entrevistadas reconoce haberse casado por arreglo e incluso una de ellas manifestó off the record oposición a la voluntad de sus padres, en su elección. Se podría decir que la noción de 
amor como proyecto abierto a la elección individual se ha impuesto, en cierto modo, a una versión menos romántica en la que las decisiones se circunscribían más fácilmente a las disposiciones del marco institucional.

Todos estos cambios, sin embargo, no erradican de la memoria el marco normativo y conceptual que permite a las personas entrevistadas interpretar la realidad y responder a las preguntas de los que las entrevistaban. Y ello no es sólo por lo apuntado hasta aquí, sino porque el modelo se aplica, en el discurso de algunas personas entrevistadas, en una relación simbólica entre la institución del bereu y la identidad catalana. Si, como decíamos más arriba, en Cataluña el modelo troncal y el sistema del bereu ha llegado a ser un referente ideológico e identitario, en este caso encontramos que prácticas que se podrían incluir en ese mismo patrón, se consideran ajenas. Dicho de otro modo, se asocia al bereu con Cataluña y se niega toda similitud con él, de las propias prácticas modélicas. Es el caso, por ejemplo, de una mujer que sostenía que el modelo generalizado de herencia en Els Ports era igualitario, pese a que ella misma reconocía que en su caso no lo había sido:

Tots eren iguals. No n'hi havie hereu, com a Catalunya, que fan a uno el hereu. No. Jo he dit hereu, però no és això (MO68: 5).

En otra entrevista se lee la siguiente intervención, que va en un sentido parecido:

A Catalunya el més gran o el més menut o el que ere mascle si n’hi havie xiques, és igual. Ú més amistat que li tenien a una xica per lo que fore, pos aquella li donaen la finca i els demés, espavileu-se [...] Jo ací no vaig vore més que un cas [...] Aquell home que va donar la llegítima al fill, no es va morir de fam perquè le van agarrar els altres fills, i els altres gendres, que sino s'haguere mort de fam. I li va millorar la finca, però la finca la va amillorar en molt poquet preu i li la van fotre els cunyats (MO81: 11).

Este tipo de afirmaciones y las que hemos visto en este apartado dejan entrever la continuidad del sistema como referente ideológico y normativo, entre las personas de más de setenta años, en la comarca de Els Ports, y especialmente entre aquellas que han conocido la realidad de los masos. Una continuidad que remite a un marco interpretativo del presente, hecho desde el pasado. Ciertamente las entrevistas pueden haber ayudado a perfilar una imagen demasiado modélica. Sin embargo, los juicios de valor de los propios entrevistados son sólo suyos y permiten entender que la lógica del modelo y las prácticas que se han asociado con él tienen una naturaleza simbólica que se capta muy bien en el discurso. Entre la generación de los sujetos a quienes se ha entrevistado y la siguiente ha habido transfor- 
maciones que atañen, fundamentalmente, a la forma de herencia, a la residencia y a las estrategias matrimoniales. Sin embargo, en el discurso de nuestros informantes se puede percibir el mantenimiento del modelo como patrón interpretativo cuyos principios, valores y lógica conocen y comparten, aunque sus prácticas familiares vayan por otros derroteros.

\section{CONCLUSIONES}

De lo visto hasta aquí se desprenden conclusiones parciales pero significativas. Se ha visto la continuidad del modelo troncal como marco de interpretación conocido por las personas de una generación que, por otra parte, tienen memoria de prácticas que no sólo sería difícil encontrar hoy entre sus descendientes, sino que muchos de ellos ni tan siquiera han protagonizado. De todos modos, no se trataba aquí de juzgar si se aplicaba hoy el modelo más o menos rígidamente. La intención era, simplemente, constatar si había memoria de un conjunto de prácticas y valores familiares más o menos coherente. Es cierto que dicha coherencia tiene algo que ver con el guión de las entrevistas y con los intereses de quienes las diseñamos y realizamos, pero la confluencia de aspectos similares en todas las entrevistas no deja lugar a dudas: el modelo sigue presente en un nivel simbólico, al menos para esta generación.

Lo que queda en la memoria del sistema troncal, tal y como se ha recogido, es, en primer lugar, un conjunto de valores y normas que rigieron en su momento decisiones tomadas y prácticas realizadas en situaciones de más o menos tensión y frente a condicionantes estructurales ante los cuales a menudo no quedaba sino seguir adelante. En segundo lugar, ese mismo elenco permite interpretar el presente para discernir cambios en el mundo familiar y más allá de él, de modo que se muestra la conciencia de que para los propios descendientes las normas y valores parecen ser distintos, así como el modelo familiar. En tercer lugar, vemos cómo un modelo seguido de forma similar en otros lugares es caracterizado como algo diferente, lejano e inconveniente, al ser identificado como propio de Cataluña.

Los datos que hemos obtenido son sumamente parciales. Para profundizar más en la cuestión habría que acercarse a las generaciones que siguen. También sería interesante aproximarse al conocimiento que se tiene en Els Ports de casos catalanes, para ver porqué surge el juicio que se efectúa sobre las propias prácticas, cuando son desarrolladas en Cataluña. Estas y otras preguntas quedan por responder. El objetivo era abrir una vía para que se puedan encontrar sus respuestas, destacando el potencial que para ello tienen las fuentes orales y la memoria. Las más de cien entrevistas realizadas 
en comarcas valencianas, en el contexto del proyecto Arxiu de la Memoria Oral Valenciana. Museu de la Paraula ofrecen materiales interesantes desde muchos puntos de vista. Por lo pronto, se trata de discursos sobre la memoria del pasado que nos interpelan en el presente y que se encuentran a disposición de quienes decidan adentrarse en ellos. Sirva este artículo como aportación a que un proyecto colectivo pueda ser compartido más allá de los bastidores en los que ha ido tomando forma con la contribución de todas las personas que hemos participado en él.

\section{BIBLIOGRAFÍA CITADA}

Albert, M.; A. Moncusí y B. Santamarina. 2005. "La memoria oral como producto institucionalizado y recurso identitario en la Comunidad Valenciana", en J. M. Valcuende y S. Narotzky (coords.), Las politicas de la memoria en los sistemas democráticos: 225-242. Sevilla: Fundación El Monte-FAAEE.

Assier-Andrieu, L. 1981. Coutume et rapports sociaux. Étude anthropologique des communautés paysannes du Capcir. París: Editions du CNRS.

Assier-Andrieu, L. 1986. "L'esprit de la maison pyrénéenne", en A. Esteban e Y-R Fonquerne (coords.), Los Pirineos. Estudios de Antropología Social e Historia. Actas del coloquio celebrado en la Casa de Velázquez: 95-109. Madrid: Casa de Velázquez.

Barrera, A. 1990. Casa, herencia y familia en la Cataluña rural. Madrid: Alianza.

Barrera, A. 1994. "Sucesión unipersonal y familia troncal en Cataluña y el norte de la Península Ibérica (Análisis comparativo)”, en D. Comas D’Argemir y J-F. Soulet (eds.), La Família als Pirineus. Andorra: Govern d'Andorra.

Bauman, Z. 2005. Amor líquido. Acerca de la fragilidad de los vínculos humanos. Madrid: FCE.

Beck, U. y E. Beck-Gernsheim. 1995. The normal chaos of love. Cambridge: Polity Press.

Bourdieu, P. 1972. "Les stratégies matrimoniales dans le système de reproduction". Annales E.C.S 27: 1105-1127.

Bourdieu, P. 2004. El baile de los solteros. Barcelona: Anagrama.

Bruner, J. 2000. Actos de significado: más allá de la revolución cognitiva. Madrid: Alianza.

Candau, J. 2000. Antropología de la memoria. Buenos Aires: Nueva Visión.

Cohen, A. P. 1985. The symbolic construction of community. Londres: Routledge.

Comas d'Argemir, D. 1980. "Sistema d'herència i estratificació social: les estratègies hereditàries en el Pirineu Aragonès". Quaderns de l'ICA 2: 26-55.

Comas d'Argemir, D. 1994. "Casa y comunidad. Ideales culturales y reproducción social", en J. J. Pujadas y D. Comas D'Argemir, Estudios de Antropologia Social en el Pirineo Aragonés: 107-122. Zaragoza: Diputación General de Aragón.

Comas d'Argemir, D. y J. Contreras. 1990. "El proceso de cambio social". Agricultura y Sociedad. Suplemento al n. ${ }^{\circ} 55$.

Comas Dellà, J. y C. Comas Cifre. 2002. Els masos valencians. Vilafranca 1800-1900. Castelló: Servei de Publicacions Diputació de Castelló.

De la Parte, I. y D. Mas. 2000. La casa a Andorra. Dues històries de família. Barcelona: Alta Fulla-Govern d'Andorra.

Eriksen, T. H. 1993. Ethnicity and nationalism. Londres: Pluto Press. 
Estrada, F. 1989. "Els folkloristes i la "familia catalana". L'Avenç 132: 22-2.

Estrada, F. 1994. "La casa al Pla d'Urgell. Transformacions econòmiques i canvis en els models familiars", en S. Ponce y Ll. Ferrer (eds.), Familia i canvi social a la Catalunya contemporània. Vic: Eumo Editorial.

Estrada, F.; X. Roigé y O. Beltrán. 1993. Entre l'amor i l'interès. El procés matrimonial a la Vall d'Aran. Tremp: Garsineu.

Ferraroti, F. 1981. Storia e storie di vita. Bari: Laterza.

Frigolé, J. 2003. Cultura y genocidio. Barcelona: Publicacions de la UB.

García Zanón, A. y R. Ferrero. 2001. "La creació d'un museu de la paraula: l'Arxiu de la Memoria Oral dels Valencians (Un projecte museogràfic)", en Fonts orals en la investigació a les terres de parla catalana. Actes de les Jornades de la CCEPC: 159-162. Barcelona: Publicacions de la Coordinadora de Centres d'Estudis de Parla Catalana.

Giddens, A. 1993. The Transformation of Intimacy. Sexuality, love and eroticism in modern societies. Cambridge: Polity Press.

Halbwachs, M. 2004 [1950]. La memoria colectiva. Zaragoza: Universidad de Zaragoza.

Hall, E. T. y P. Du Gay (eds.). 1996. Questions of cultural identity. Londres: Sage.

Hamer, J. H. 1984. "Identity, Process, and Reinterpretation. The Past Made Present and the Present Made Past". Anthropos 89: 181-190.

Hobsbawm, E. y T. Ranger (eds.). 1988. L'invent de la tradició. Vic : Eumo.

Le Play, F. 1884. L'organisation de la famille selon le vrai modèle signalé par l'histoire de toutes les races et de tous le temps. París.

Lisón, C. 1976. "Estructura antropológica de la familia en España", en R. Carballo (ed.), La familia. Diálogo recuperable: 37-51. Madrid: Karpos.

Malkki, L. 1995. Purity and Exile: Violence, memory and national cosmology among Hutu refugees in Tanzania. Chicago: The University of Chicago Press.

McDonogh, G. W. 1989. Las buenas familias de Barcelona. Barcelona: Omega.

Mira, J. F. 1978. Els valencians $i$ la terra. València: Eliseu Climent.

Mira, J. F. 1980. "La estrategia matrimonial: un difícil equilibrio", en Vivir y hacer historia: 73-104. Barcelona: Península.

Mira, J. F. 1984. Critica de la nació pura. València: Eliseu Climent.

Moncusí, A. 2004. "Investigació antropològica i patrimonialització: reflexions a la llum de dues recerques". Arxius de Ciències Socials 9: 87-106.

Moncusí, A. 2006. "Testimonios personales: fuentes orales del patrimonio. El Arxiu de la Memòria Oral Valenciana. Museu de la Paraula". Boletín del Instituto Andaluz de Patrimonio Histórico 58: 115-116.

Pereiro, X. 2004. "Apuntes de Antropología y Memoria". O Fiadeiro/El Filandar 15: 75-81.

Pitarch, V. 2003. "Presentació", en G. Huguet [1969], Els valencians de secà: 11-81. Castelló: Publicacions de la Universitat Jaume I.

Prat, J. 1989. "El pairalisme com a model ideològic". L'Avenc 132: 34-53.

Pujadas, J. J. 1993. Etnicidad. Identidad cultural de los pueblos. Madrid: Eudeba.

Pujadas, J. J. 2000. "El método biográfico y los géneros de la memoria". Revista de Antropología Social 9:127-158.

Pujadas, J. J.; M. Soronellas y G. Casal. 2007. Cada casa és un món. Família, economia $i$ arquitectura a la Cerdanya. Barcelona: Generalitat de Catalunya.

Querol, E. (coord.) 1995. La comarca dels Ports. Barcelona: Publicacions de l'Abadia de Montserrat.

Ricoeur, P. 1999. La lectura del tiempo pasado: Memoria y olvido. Madrid: Arrecife. 
Roigé, X. 1997. La casa aranesa. Tremp: Garsineu.

Roigé, X. 2002. "Canvis en la família i les relacions intergeneracionals", en Ll. Flaquer (coord.), Informe sobre la situació de la família a Catalunya. Un intent de diagnòstic: 60-75. Barcelona: Generalitat de Catalunya.

Segalen, M. 1992. Antropología histórica de la familia. Madrid: Taurus.

Soronellas, M. 2002. Pagesos en un món de canvis. Família i associacionisme agrari a la Selva del Camp, segles XVIII, XIX $i$ XX. Tesis doctoral, Universitat Rovira i Virgili, Tarragona.

Thomas, W. I. y F. Znaniecki (1958). The polish peasant in Europe and America. Nueva York: Dover.

Thompson, P. 1988. La voz del Pasado. Historia oral. València: Alfons el Magnànim.

Thompson, P. 2004. "Historia, memoria y pasado reciente". Anuario de la Facultad de Humanidades y Artes de la Universidad de Rosario 20: 15-34.

Todorov, Z. 2000. Los abusos de la memoria. Barcelona: Paidós.

Valcuende, J. M. y S. Narotzky (coords.) 2005. Las políticas de la memoria en los sistemas democráticos: Poder, cultura y mercado. Sevilla: Fundación El Monte-FAAEE.

Vallés, M. S. 1999. Técnicas cualitativas de investigación social. Reflexión metodológica y práctica profesional. Madrid: Síntesis.

Fecha de recepción: 28 de septiembre de 2009

Fecha de aceptación: 17 de agosto de 2010 


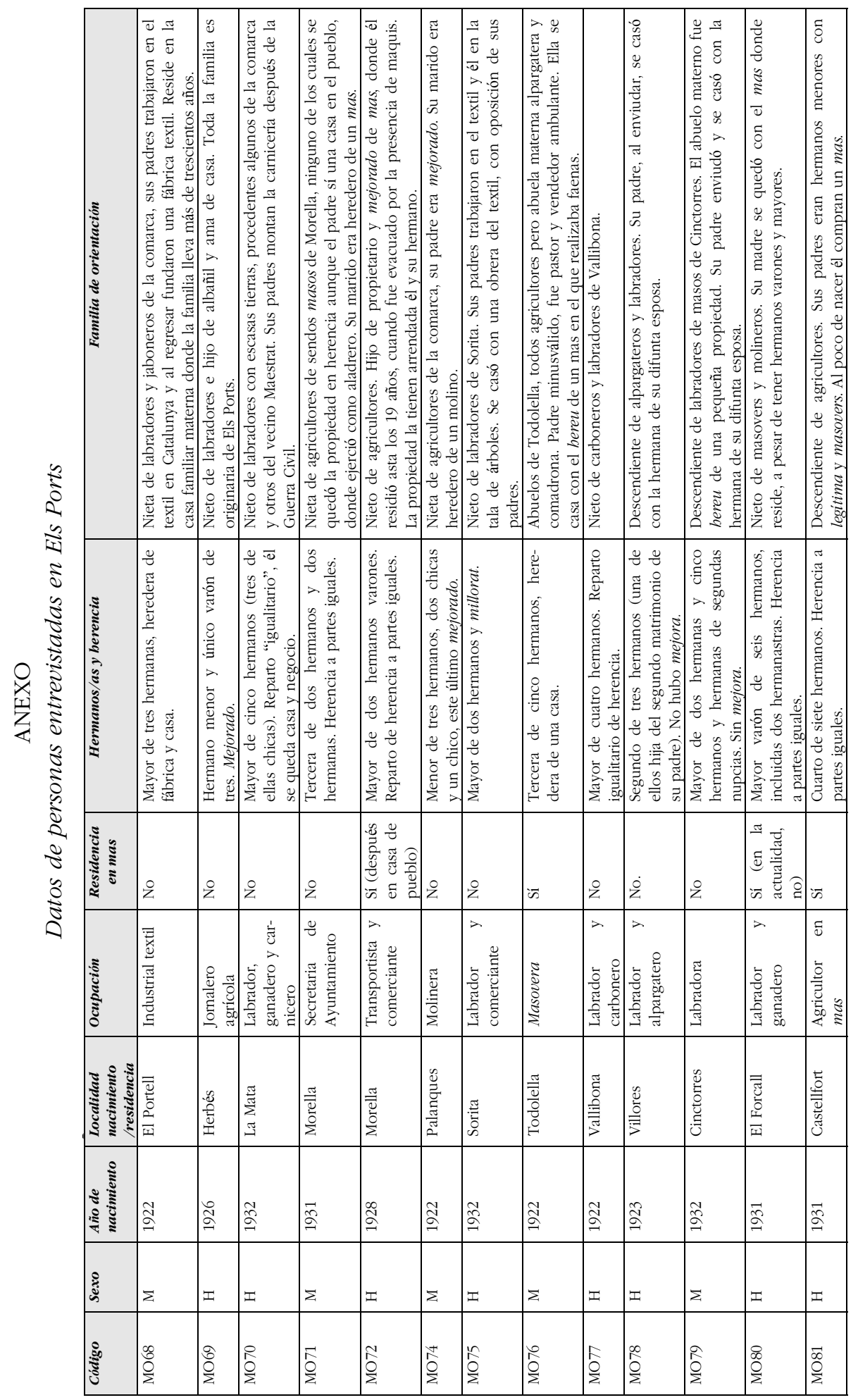

